\title{
Fragilidad y degradación ambiental en áreas rurales de la diagonal árida templada argentina*
}

\section{Fragility and environmental degradation in rural areas of the temperate arid argentinian diagonal}

\author{
Julia Inés Gabella ${ }^{1}$ y Alicia María Campo ${ }^{2}$
}

\begin{abstract}
RESUMEN
El objetivo de este trabajo consiste en analizar las características climáticas del partido de Patagones localizado en el extremo sur de la región pampeana argentina, determinar su inserción dentro de la diagonal árida templada argentina y entenderla como un área frágil de transición climática, expuesta a procesos degradatorios derivados de la acción antrópica. Se combinaron enfoques cualitativos y cuantitativos y se caracterizó climáticamente el área mediante la aplicación del método de balances hídricos y el cálculo y análisis del Índice de Precipitación Estandarizado (IPE o SPI). Se observó en el partido de Patagones una desconexión permanente entre el binomio condiciones climáticas-medio natural y las lógicas de producción-explotación capitalistas implementadas en el área, lo cual han generado la degradación ambiental de este espacio rural.
\end{abstract}

PAlABRAS CLAVE: áreas rurales; fragilidad; diagonal árida templada argentina; degradación ambiental.

* El presente trabajo se realizó en el marco del proyecto de investigación "Geografía física aplicada al estudio de la interacción sociedad-naturaleza. Problemáticas a diferentes escalas témporo-espaciales" bajo la dirección de la Dra. Alicia M. Campo, (24/G067), financiado por el Departamento de Geografía y Turismo de la Secretaría General de Ciencia y Tecnología (SGCyT) de la Universidad Nacional del Sur (UNS).

${ }^{1}$ Doctora en Geografía, Universidad Nacional del Sur (UNS)-Consejo Nacional de Investigaciones Científicas y Técnicas (CONICET), julitagabella@gmail.com.

${ }^{2}$ Investigadora Independiente del Consejo Nacional de Investigaciones Científicas y Técnicas (CONICET) y Profesora Titular de la Universidad Nacional del Sur (Departamento de Geografía y Turismo) (UNS), amcampo@uns.edu.ar. 


\begin{abstract}
The aim of this paper is to analyze the climatic characteristics of Patagones district, located in the south of pampeana region (Argentina). We also determine its insertion into the temperate arid argentinian diagonal to understand it as a fragile area of climate transition, exposed to degradation processes derived from human action.

Qualitative and quantitative approaches were combined in order to arrive to the objetive. The climatic characterization of the area was conducted by applying the water balance method and the calculation and analysis of the Standardized Precipitation Index (SPI). It was found in Patagones district a permanent disconnection between natural and climatic conditions and the logics of capitalists' production, which are not adapted to the natural conditions of the territory and have generated environmental degradation of the rural space.
\end{abstract}

KEY WORDS: rural areas; fragility; temperate arid argentinian diagonal; enviromental degradation.

\title{
INTRODUCCIÓN
}

Los sucesivos modelos de desarrollo que se instauraron en la Argentina a lo largo de su historia generaron diversos procesos de ocupación y organización del espacio y condicionaron los modelos de gestión productivos. Los espacios rurales dedicados y orientados a las actividades de producción primaria para los mercados externos fueron una pieza clave en la organización nacional. Cada región del país, en función de sus características y aptitudes medioambientales desarrolló a lo largo de los años la producción de diferentes bienes que condicionaron la estructura y organización territorial y, en función de cada contexto internacional y nacional, estos espacios lograron un mayor o menor grado de desarrollo.

La región pampeana, gracias a las favorables condiciones climáticas para la agricultura y ganadería, se convirtió en un espacio propicio para desarrollar el modelo agroexportador y sostenerlo a través de diferentes períodos históricos. Las áreas rurales localizadas al sur y suroeste de esta extensa región se vieron alteradas por la expansión de este modelo y así, sin importar las diferenciaciones del medio natural y particularidades de cada zona, se implementaron sistemas de producción agropecuaria con tecnologías propias de áreas más húmedas y fértiles dominadas por pastizales pampeanos. El avance de la frontera agropecuaria en estos espacios no solo implicó un cambio productivo, sino que también generó modificaciones en las redes sociales y en las configuraciones del territorio.

Las áreas rurales del extremo sur de la provincia de Buenos Aires pertenecientes al partido de Patagones representan un ejemplo más de esta dinámica. En el transcurso del siglo xx así como también en años recientes las lógicas de 
producción netamente agrícolas se introdujeron en esta área marginal extra pampeana. La concepción de marginalidad se asocia a características naturales que condicionaron y condicionan en la actualidad, la posibilidad de este espacio de incorporarse a las lógicas de producción capitalistas. Estas lógicas implementadas en el área según los vaivenes climáticos y económicos generaron la utilización de los recursos naturales con mayor presión, sin importar los impactos y desestimando las consecuencias ambientales.

Los objetivos de este trabajo consisten en analizar las características climáticas del área de estudio para poder determinar su ubicación dentro de la diagonal árida templada argentina y entenderla como un área frágil de transición climática, expuesta a procesos degradatorios derivados de la acción antropogénica.

\section{LA INSERCIÓN DE PATAGONES DENTRO DE LA DIAGONAL ÁRIDA TEMPLADA ARGENTINA}

El partido de Patagones, representa una zona de transición entre lo que se denomina la Pampa Húmeda y la Pampa Seca. Su posición lo convierte en un espacio de articulación socio histórico y económico entre las regiones pampeana y patagónica (figura 1). Es el partido más austral y extenso de la provincia de Buenos Aires, Argentina, con una superficie de $13.597 \mathrm{~km}^{2}$.

Una vasta llanura constituye el marco natural predominante de la región, con muy pocos accidentes geográficos que alteren su interminable monotonía (Sili, 2000). Sin embargo sí son notorias las diferencias climáticas, que reflejan de norte a sur, una progresiva aridez. Dominan los sistemas aterrazados surcados por los ríos alóctonos Colorado y Negro, de origen cordillerano y, es allí donde las características se tornan netamente patagónicas (Capelli de Steffens y Campo de Ferreras, 1994). El partido presenta la ingresión por el oeste, de las estribaciones de las terrazas patagónicas cubiertas por monte natural. Se trata de planicies solo interrumpidas por suaves ondulaciones medanosas o calcáreas, pero en ningún caso, alcanzan alturas importantes (Sánchez et al., 1998). Los suelos del partido poseen una textura franco arenosa, susceptibles a la erosión eólica, con niveles de materia orgánica muy bajos. Los materiales originarios son arenas finas y limos transportados por el viento y depositadas sobre tosca y rodados líticos o materiales limo arenosos más antiguos, débilmente consolidados (Sánchez et al., 1998). La aptitud del suelo se encuentra limitada en general por las condiciones climáticas predominando un déficit hídrico anual y vientos desecantes y erosivos. Las limitaciones edáficas están relacionadas con la baja capacidad de retención de humedad y alta susceptibilidad a la erosión eólica (Peña Zubiate et al., 1998). 
FIGURA 1

LOCALIZACIÓN DEL ÁREA DE ESTUDIO
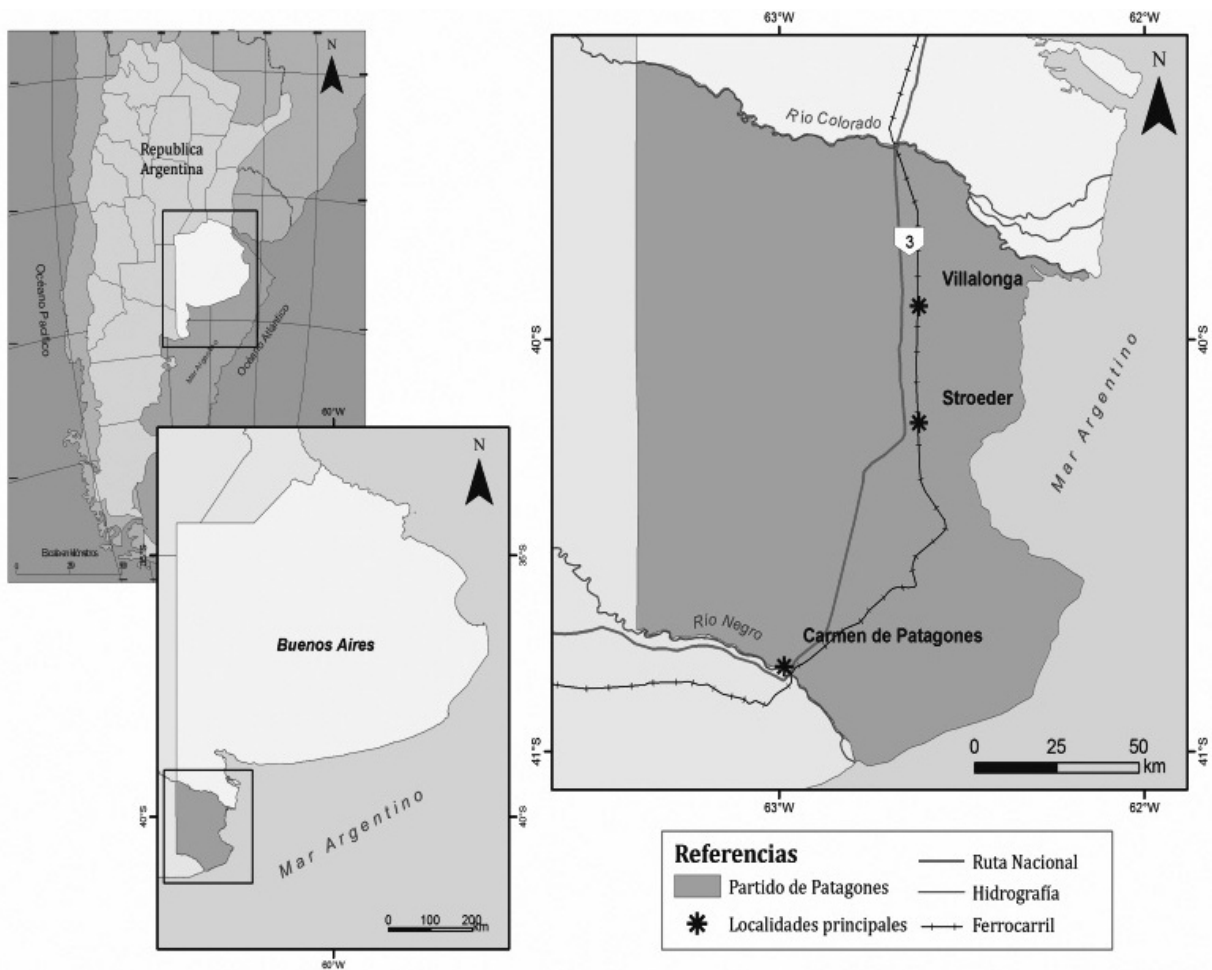

Fuente: elaborado por Julia Gabella sobre la base de cartografía del IGN, 2014.

Patagones presenta la influencia de un clima templado de transición con predominio de masas de aire tropicales y polares estas últimas con bajo contenido de humedad. El área registra valores medios anuales de temperatura comprendidos entre $14^{\circ} \mathrm{C}$ y $20^{\circ} \mathrm{C}$ y estaciones térmicas bien diferenciadas, es decir, veranos e inviernos rigurosos y primaveras y otoños moderados. Los rasgos de continentalidad aumentan de noreste a suroeste evidenciándose variaciones importantes en los montos de precipitación y cambios graduales en los valores medios de temperatura (Capelli de Steffens y Campo de Ferreras, 1994; Campo et al., 2004).

Estudios realizados por Bohn et al. (2011); Gil et al. (2009); Campo et al. (2009), Gabella et al. (2010); Piccolo et al. (2002) afirman que en la región exis- 
ten variaciones climáticas asociadas a una gran variabilidad en los eventos y montos de las precipitaciones. La tendencia en el área demuestra la ocurrencia de períodos de varios años con excesos de humedad, donde los valores se encuentran por encima de la media histórica y otros con déficits, donde los montos anuales no logran alcanzar el valor promedio. «La suma de estas desviaciones positivas o negativas, por encima o por debajo del promedio anual, da lugar al movimiento cíclico o marcha secular, que en definitiva significa la ocurrencia de varios años húmedos, secos o medianamente secos» (Glave, 2006: 19).

Históricamente se le asignó a esta zona diferentes denominaciones climáticas, acordes a las variaciones que reconocían distintos autores. Según Köppen y Geiger (1936) quienes basan su clasificación climática en las precipitaciones y las temperaturas caracterizando cada región por la vegetación natural, el partido de Patagones estaría bajo el dominio de un clima «árido estepario y árido desértico». En el Mapa Ecológico Argentino Papadakis (1978), ubica a Patagones dentro de las regiones ecológicas «Pampa agrícola Sur y Bosque Ralo Pampeano». Chiozza y Figueira (1981) lo caracterizan climáticamente como «semiárido de las planicies y semiárido de las mesetas» y Bruniard (1999), sobre la base de los regímenes hídricos, la clasifica como un área de estepa arbustiva y matorral semidesértico.

El Atlas de Zonas Áridas de América Latina y el Caribe (2010) y el Observatorio Nacional de la Degradación de Tierras y Desertificación utilizan el Índice de Aridez propuesto por $\mathrm{UNEP}^{3}$ el cual expresa la relación entre la precipitación anual promedio y la evapotranspiración potencial en un área determinada e incluyen al partido de Patagones dentro de la clasificación de tierras secas específicamente entre una zona subhúmeda seca, semiárida y árida (Verbist et al., 2010).

Si bien cada autor elige una clasificación diferente todos coinciden en que el área de estudio representa una zona de transición climática entre un ambiente semiárido a árido reflejado en su vegetación nativa. La misma constituye un ecotono entre las provincias fitogeográficas del Monte y del Espinal con individuos vegetales xerófilos que se adaptan a las condiciones ambientales de aridez.

Patagones presenta una continuidad espacial del sistema rural pampeano pero en una zona naturalmente diferenciada a partir de la dominancia florística

\footnotetext{
${ }^{3}$ El índice define la aridez mediante la interrelación de la temperatura con las precipitaciones, basándose en el supuesto que con la temperatura aumenta correlativamente la evapotranspiración. Se utiliza para la clasificación y delimitación de las tierras. Divide las tierras en húmedas y secas, las zonas áridas a su vez son clasificadas en hiperáridas, áridas, semiáridas y sub húmedas secas (Atlas Mundial de Desertificación, UNEP, 1997).
} 
(Petagna del Río y Ferrera, 1998). Desde el punto de vista fitogeográfico el área se encuentra bajo el Dominio Chaqueño, el mismo posee endemismos genéricos y específicos, caracterizados por la abundancia de ciertas familias y géneros. Puede subdividirse en varias provincias fitogeográficas, de las cuales solo dos se hacen presentes en la región de interés. La provincia del Monte es la dominante. Predominan en forma absolutas las especies xerófilas. Solo en la margen de ríos o lagunas se hallan especies mesófilas o higrófilas. Dominan las estepas arbustivas xerófilas, psamófilas o halófilas. También hay bosques marginales de mimosoideas. Fisonómicamente es un mosaico de tres tipos de vegetación: la estepa arbustiva climáxica dominado por especies de la familia Zygophyllaceae; las estepas edáficas de arbustos halófitos como Suaeda divaricata, Atriplex spp., Alleronfea vaginata y el bosque dominado en la mayoría de los casos por especies del género Prosopis. Esta comunidad boscosa es característica de los suelos con napa freática poco profunda de la porción septentrional de la provincia del Monte. El bosque xerófilo, forma amplios ecotonos con las provincias fitogeográficas del Espinal y Patagónica. Se trata de un matorral más o menos denso con arbustos que alcanzan los 1,5 y 3 metros de altura, entre los cuales se desarrolla una estepa herbácea de escasa cobertura con predominio de gramíneas bajas. La comunidad climax está formada por la asociación de: Larrea divaricata «jarilla», Geoffroea decorticans «chañar», Condalia microphylla «piquillín», Prosopis alpataco «alpataco», Chuquiraga erinacea «chilladora». Además es frecuente encontrar, Bromus brevis "cebadilla pampeana», Stipa tenuis «flechilla fina», Stipa ambigua "paja vizcachera» entre otras, como así dicotiledóneas $c$ «trébol carretilla», Erodium cicutarium, «alfilerillo», Baccharis ulicena «yerba de la oveja» (Pezzola et al., 2004).

La provincia del Espinal denominada también como una subformación del Monte Oriental presenta tres distritos. El distrito del Ñandubay, del Algarrobo y del Caldén. A pesar que no presenta muchos endemismos se trata de una eco-región singular, ya que solo está presente en la República Argentina. El distrito del Caldén se extiende por el centro y sur de San Luis, suroeste de Córdoba, centro de La Pampa, sur de Buenos Aires hasta el valle del río Colorado y al noreste de río Negro se han citado formaciones arbustivas que llegan casi hasta la costa atlántica, abarcando aproximadamente $40.000 \mathrm{~km}^{2}$. En general, estos límites son muy imprecisos, ya que forma extensos ecotonos con la eco-región del Monte, donde algunos de sus componentes invaden comunidades diferentes mientras que, donde limita con la región de los pastizales pampeanos, su área original ha sido reducida y alterada, como producto del desmonte y expansión de la frontera agrícola (SAyDS, 2006). El distrito se caracteriza por la abundancia de Prosopis caldenia que forma bosques xerófilos 
más o menos densos. Existen también áreas cubiertas por sabanas de gramíneas, dunas de vegetación psamófila y suelos salados con matorrales o estepas halófilas. En la figura 2 se visualizan algunas de las especies descriptas.

\section{FIGURA 2}

\section{IMÁGENES DE LA VEGETACIÓN NATIVA DEL ÁREA DE ESTUDIO}

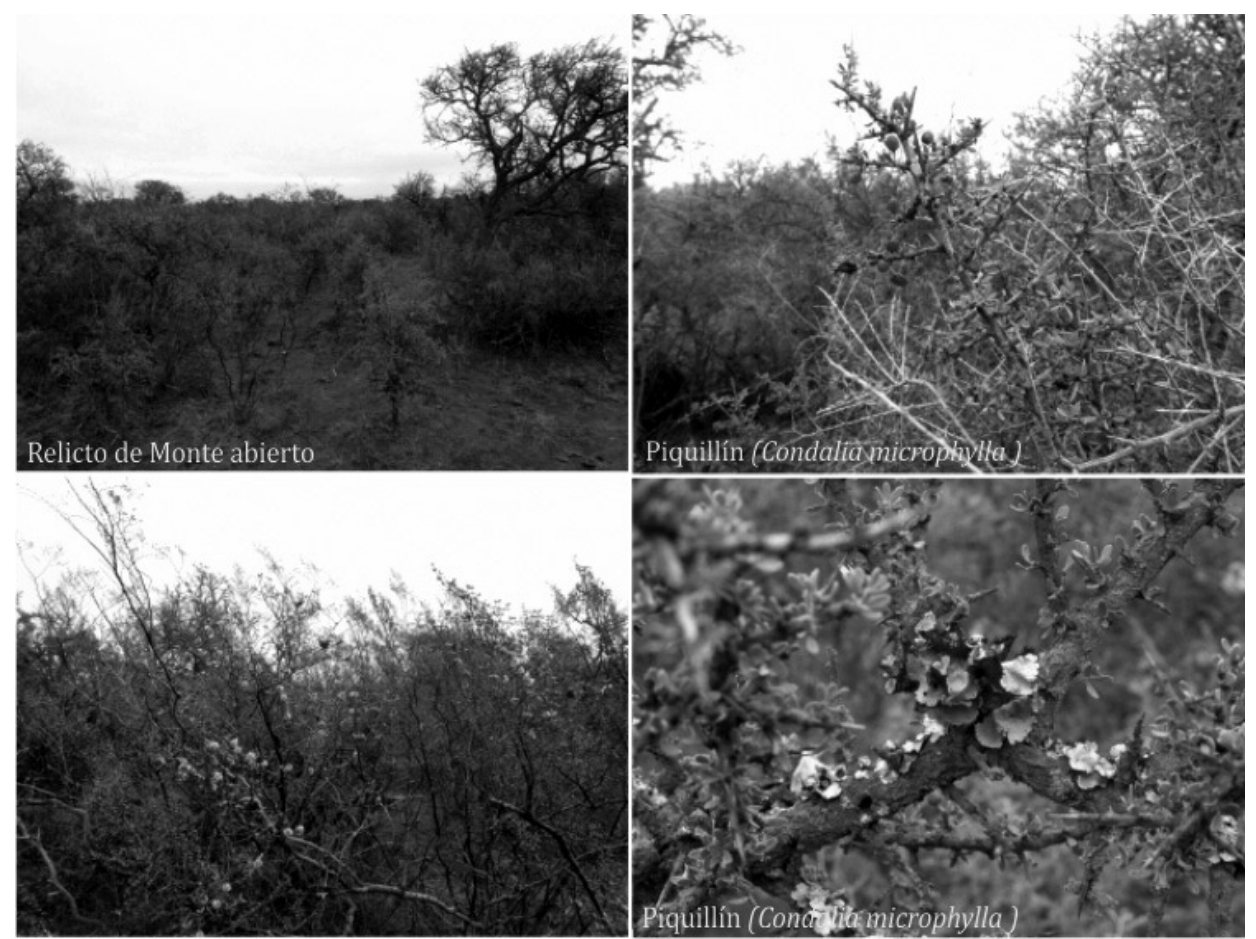

Fuente: fotografías de Julia Gabella, 2014.

Por su carácter de borde climático entre estos dos ambientes y la variabilidad y alternancia de periodos húmedos y secos se considera esta área inserta dentro de la denominada diagonal árida templada argentina. La Diagonal Árida en la Argentina abarca una gran extensión latitudinal y por ende, diversos tipos de climas. Para delimitar su ubicación se consideró la condición de «Templada» por encontrarse el área de estudio dentro de la zona planetaria de climas templados. Mancini et al. (2004) evaluaron los cambios de esta región en su desplazamiento y localización a través de estudios geomorfológicos y paleontológicos lo que evidencia su existencia desde el Holoceno medio. 
FIGURA 3

IMÁGENES DEL PAISAJE RURAL OBJETO DE ESTUDIO

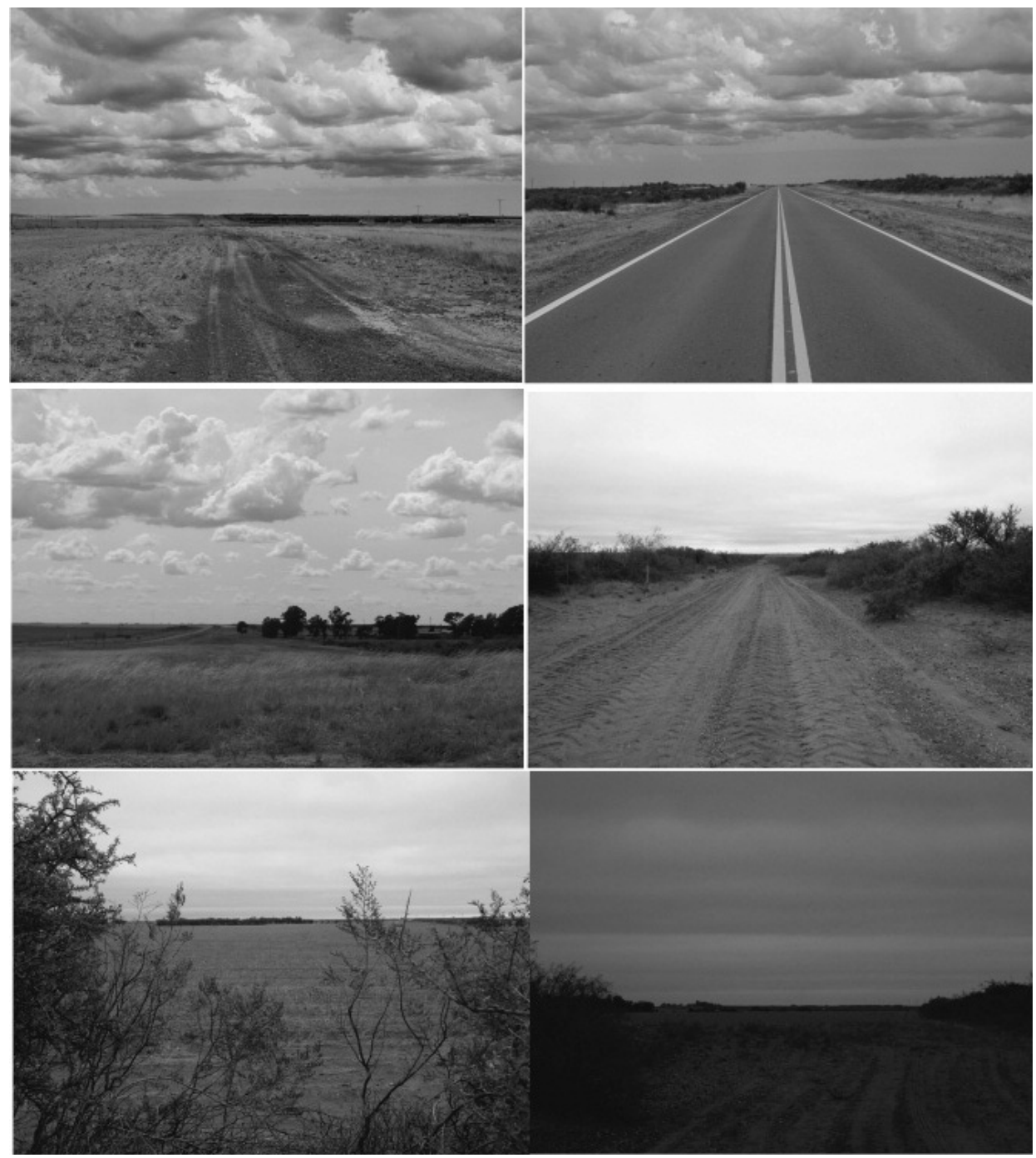

Fuente: fotografías de Julia Gabella, 2014.

Bruniard (1982) la definió como una extensa y a su vez estrecha franja, de ambientes áridos sucesivos, con escasas precipitaciones, que interrumpen la continuidad de las zonas húmedas. Atraviesa sesgadamente el continente,

Estudios Geográficos, Vol. LXXVII, 281, pp. 491-519, julio-diciembre 2016

ISSN: 0014-1496, eISSN: 1988-8546, doi: 10.3989/estgeogr.201616 
desde el norte de Perú, hasta las costas patagónicas, con una orientación en sentido noroeste-sureste. Puede considerarse como una gran unidad fisiográfica, un espacio con caracteres propios, derivados de su común aridez, aunque también representa un límite climático lineal y real, en el cual las áreas al norte y noreste quedan bajo el dominio de climas más húmedos, mientras que hacia el sur y suroeste, lo hacen climas más áridos.

Capelli y Campo (1994) demostraron que en el suroeste bonaerense es notoria la presencia meridional de la Diagonal Árida coincidente con la línea demarcatoria de las zonas de influencia de los anticiclones subtropicales del Atlántico Sur y del Pacífico Sur. En la figura 3 se observan ejemplos del paisaje rural del partido de Patagones y las características de aridez descriptas.

\section{Metodología}

Se combinaron los enfoques cualitativos y cuantitativos a lo largo del proceso de investigación (Hernández Sampieri, 2003). Madsen y Adriansen (2004) afirman que el combinar datos cualitativos y cuantitativos y utilizar diferentes métodos constituye un reto poco utilizado para estudios en las áreas rurales. El uso del espacio rural depende tanto de las características físicas como de las prácticas y valores de los actores sociales de ese territorio.

En cuanto a la recopilación de datos se recurrió a fuentes de información primaria y secundaria. Las primarias incluyen el trabajo de campo, la observación directa e indirecta y entrevistas. Las fuentes de información secundarias incluyen: búsqueda y recopilación bibliográfica, datos estadísticos, cartografía general y específica del área.

Para la caracterización climática del área de estudio se utilizaron registros térmicos y pluviométricos. Se recopilaron datos de diferentes estaciones meteorológicas localizadas en distintos sectores del partido, se realizaron análisis estadísticos básicos y se elaboraron balances hídricos. Los datos climatológicos mensuales y anuales de precipitación y temperatura fueron suministrados por el Servicio Meteorológico Nacional (SMN) y el Instituto Nacional de Tecnología Agropecuaria (INTA).

Respecto a la información climática se utilizaron datos climatológicos mensuales y anuales de precipitación y temperatura suministrados por el Servicio Meteorológico Nacional (SMN) para la localidad de Viedma, serie 1971-2010 y el Instituto Nacional de Tecnología Agropecuaria (INTA) para la localidad de Hilario Ascasubi, serie 1966-2008. Los registros pluviométricos más antiguos del partido fueron recopilados en las localidades de Stroeder y Carmen de Pa- 
tagones. En Stroeder se contó con la base de datos pluviométricos de la Asociación Rural, provenientes de la Estación del Ferrocarril para el periodo 1940-2010 y en Carmen de Patagones, la Chacra Experimental de Patagones proveyó una serie completa para el periodo 1828-1927. Del Ministerio de Agricultura, Ganadería y Pesca de la Nación Argentina (MAGyP) se utilizaron registros de precipitación mensuales, serie 1998-2010 en las localidades de Cardenal Cagliero, Carmen de Patagones, José B. Casas, Stroeder y Villalonga. El resto de los datos fueron brindados por dueños de establecimientos agropecuarios, con diferencias en cuanto al periodo de años registrados (tabla 1).

TABLA 1

FUENTES Y PERÍODOS ANALIZADOS EN LA INFORMACIÓN CLIMÁTICA

\begin{tabular}{l|c|l}
\hline \multicolumn{1}{c|}{$\begin{array}{c}\text { Registros de } \\
\text { precipitación/estación }\end{array}$} & Período & \multicolumn{1}{c}{ Fuente } \\
\hline Chacra Experimental Patagones & $1898-1927$ & INTA \\
\hline $\begin{array}{l}\text { Hilario Ascasubi } \\
\text { Establecimiento agropecuario en } \\
\text { el área de José B. Casas }\end{array}$ & $1926-2014$ & INTA \\
\hline Stroeder & $1940-2010$ & FFCC/Sociedad Rural \\
\hline $\begin{array}{l}\text { Viedma } \\
\text { 3 establecimientos agropecuarios } \\
\text { en el área de Patagones }\end{array}$ & $1995-2010$ & Productores Agropecuarios \\
\hline Cardenal Cagliero-Carmen de & Productor Agropecuario \\
Patagones-José B. Casas-Stroeder- & $2000-2010$ & Ministerio de Asuntos Agrarios \\
\hline Villalonga & Pervicio Meteorológico Nacional \\
\hline Registros de temperatura/estación & Periodo & \\
\hline Hilario Ascasubi & $1966-2014$ & INTA \\
\hline Viedma & $1971-2010$ & Servicio Meteorológico Nacional \\
\hline
\end{tabular}

Fuente: elaborado por Julia Gabella, 2014.

El método utilizado para la realización de los balances hídricos fue el de Thornthwaite y Mather (1957). Este método utiliza datos de precipitación y de temperatura y considera la evapotranspiración potencial o necesidad de 
agua, la cual se calcula a partir de los datos de latitud y la temperatura media mensual (Campo et al., 2004). El análisis de los balances hídricos posibilita la zonificación climática y explica las variaciones en el tiempo y en el espacio de las condiciones climáticas y sus consecuencias en el régimen hidrográfico. Es una herramienta útil para mostrar la transición entre climas y la variación de los tipos climáticos estableciendo límites más precisos que los logrados con los valores de precipitación anual o mensual (Capelli de Steffens y Campo de Ferreras, 1994). Este enfoque es sumamente importante para el área de estudio debido a su ubicación dentro de la Diagonal Árida y a las problemáticas socioeconómicas que se manifiestan luego de severos episodios de sequías.

Como resultado de la aplicación de este cálculo se obtiene el índice hídrico, el índice de aridez y el índice de humedad. El primero es la relación entre el exceso, la deficiencia y la necesidad de agua. Los valores obtenidos permiten categorizar diferentes tipos climáticos. El segundo es resultante de la relación del déficit de agua con la evapotranspiración potencial. El tercero se define como el conjunto de los excesos de agua. Este método también permite la identificación de los tipos climáticos de las localidades analizadas. Thornthwaite define nueve tipos climáticos de acuerdo con el índice hídrico: perhúmedo (A), húmedo (B4, B3, B2, B1), subhúmedo húmedo (C2), subhúmedo seco (C1), semiárido (D) y Árido (E) (Capelli de Steffens y Campo de Ferreras, 1994; Duval et al., 2012).

Asimismo se aplicó también el Índice de Precipitación Estandarizado (IPE o SPI de su sigla en inglés) a los datos de una estación representativa del partido (Stroeder) por su localización y extensión de datos recopilados. El índice fue desarrollado por Mckee et al. (1993) para mejorar la detección del inicio de las sequías y su ulterior monitoreo. Actualmente es utilizado por ser una herramienta versátil que permite cuantificar tanto déficit como excesos de precipitación. El cálculo del IPE consiste en ajustar una distribución teórica (generalmente la Gamma de dos parámetros) a la serie de precipitación usada de referencia. Los parámetros de la distribución ajustada se usan para convertir la serie de precipitación en una distribución normal estandarizada, con media 0 y varianza 1 , en cuya abscisa se encuentra el IPE. Los valores negativos indican déficit y los positivos superávit.

El IPE permite trabajar con múltiples escalas temporales (2, 3, 6 y 12 meses) que varían en función del objetivo de la investigación. En el área de estudio se seleccionó una escala de 12 meses debido a la extensión del período analizado (70 años para la serie 1940-2010). Se cuantificó de esta manera, las condiciones de déficit o exceso de precipitación de un lugar según escalas temporales. Esto permitió que sea apto para el estudio de sequías cortas (im- 
portantes para la agricultura) o muy prolongadas (relevantes para evaluar la disponibilidad de agua subterránea, la escorrentía y los niveles de lagos o reservorios de agua). Por ello es aplicable al ámbito de la meteorología, agricultura e hidrología superficial.

En cuanto a la elaboración de la cartografía se digitalizaron mapas derivados de cartografía analógica básica (cartas topográficas del Instituto Geográfico Nacional [IGN] y fotografías aéreas) utilizando el programa ArcGIS 9.3®.

\section{Resultados}

\section{Distribución espacial y temporal de las precipitaciones}

El promedio de precipitaciones para el partido de Patagones, sobre la base de la información climatológica de tres localidades para un total de 70 años, es de $407 \mathrm{~mm}$. Si se consideran los valores individuales de cada una de las estaciones seleccionadas, los montos disminuyen hacia el sur, lo que indicaría la influencia de la Diagonal Árida (figura 4).

FIGURA 4

PRECIPITACIONES MEDIAS ANUALES PARA EL PARTIDO DE PATAGONES (1940-2010)

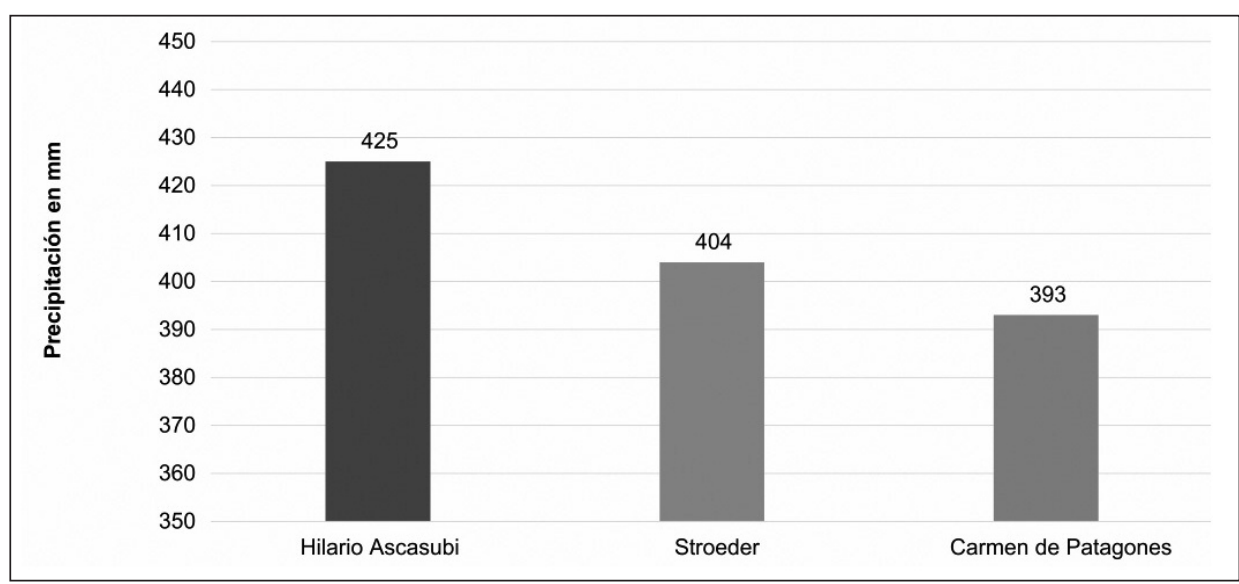

Fuente: elaborado por Julia Gabella, 2014.

En cuanto a la distribución estacional de precipitaciones Capelli et al. (1979) afirman que para el periodo 1901-1950, el promedio anual de precipitaciones en la localidad de Patagones fue de $330 \mathrm{~mm}$, con pocas variaciones 
estacionales, registrándose máximos en primavera y mínimos en invierno, característica típica de un clima templado de transición. Para los siguientes años (1951-2010) las lluvias alcanzaron una media anual de $402 \mathrm{~mm}$, lo que evidenció la influencia de un periodo más húmedo, que comenzó a partir de la década del setenta y continuó en las décadas del ochenta y noventa, con valores de 417; 380 y 433 mm respectivamente.

En el análisis de la distribución mensual de la serie 2001-2010 se registraron picos máximos en los meses de enero, febrero y marzo. Esto manifiesta una leve tendencia positiva en el aumento de precipitaciones en la estación estival asociado a dinámicas que afectan también a la región del suroeste bonaerense (Gabella et al., 2010).

\section{La condición de aridez: cálculo y análisis de balances hídricos}

Se realizaron los balances hídricos de dos localidades ubicadas en los límites extremos del partido (figura 5). Al norte, Hilario Ascasubi, perteneciente al partido de Villarino y al sur, la ciudad de Viedma, capital de la provincia de

\section{FIGURA 5}

\section{LOCALIZACIÓN DE LAS ESTACIONES METEOROLÓGICAS SELECCIONADAS PARA EL ANÁLISIS DE BALANCES HÍDRICOS}

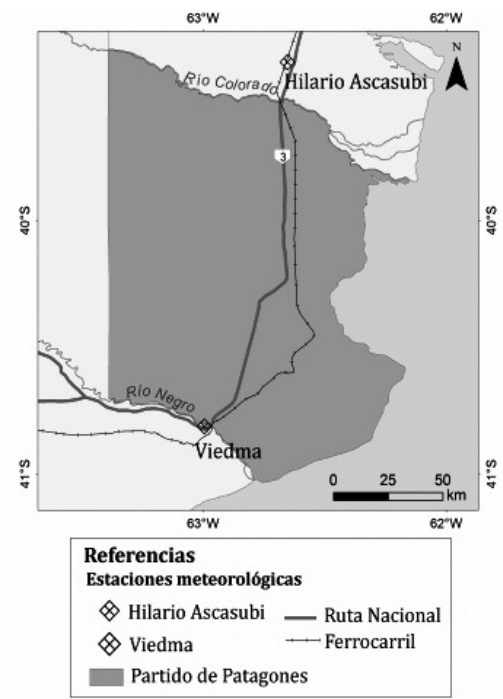

Fuente: elaborado por Julia Gabella, sobre la base de cartografía obtenida del IGN, 2014. 
Río Negro. Si bien ambas localidades no pertenecen al partido de Patagones, por su proximidad y ubicación hacen que quede comprendido entre estas dos. Se utilizó la serie 1971-2010 y se realizó un balance por década. En total se analizaron y compararon temporal (entre décadas) y espacialmente (entre localidades) un total de ocho balances hídricos.

Los balances realizados para la localidad de Hilario Ascasubi presentaron un comportamiento similar a lo largo de los años analizados con algunas diferencias para la primera y última década. Esta localidad presenta un déficit de agua a partir del mes de octubre hasta inicios del otoño (abril-mayo, con un promedio de $265,21 \mathrm{~mm}$ ), en algunos casos se extiende hasta comienzos del invierno (como en el periodo 2001-2010). La humedad del suelo se repone durante el otoño, hasta inicio y mediados de invierno con un promedio de $30,34 \mathrm{~mm}$. En agosto y septiembre comienza la utilización hasta agotarse en el mes de noviembre, donde se repite e inicia el ciclo de déficit nuevamente. En ninguna de las décadas se han registrado excesos, el índice de humedad toma el valor 0 , en cada serie analizada (figura 6).

FIGURA 6

BALANCES HÍDRICOS DE HILARIO ASCASUBI (1971-2010)

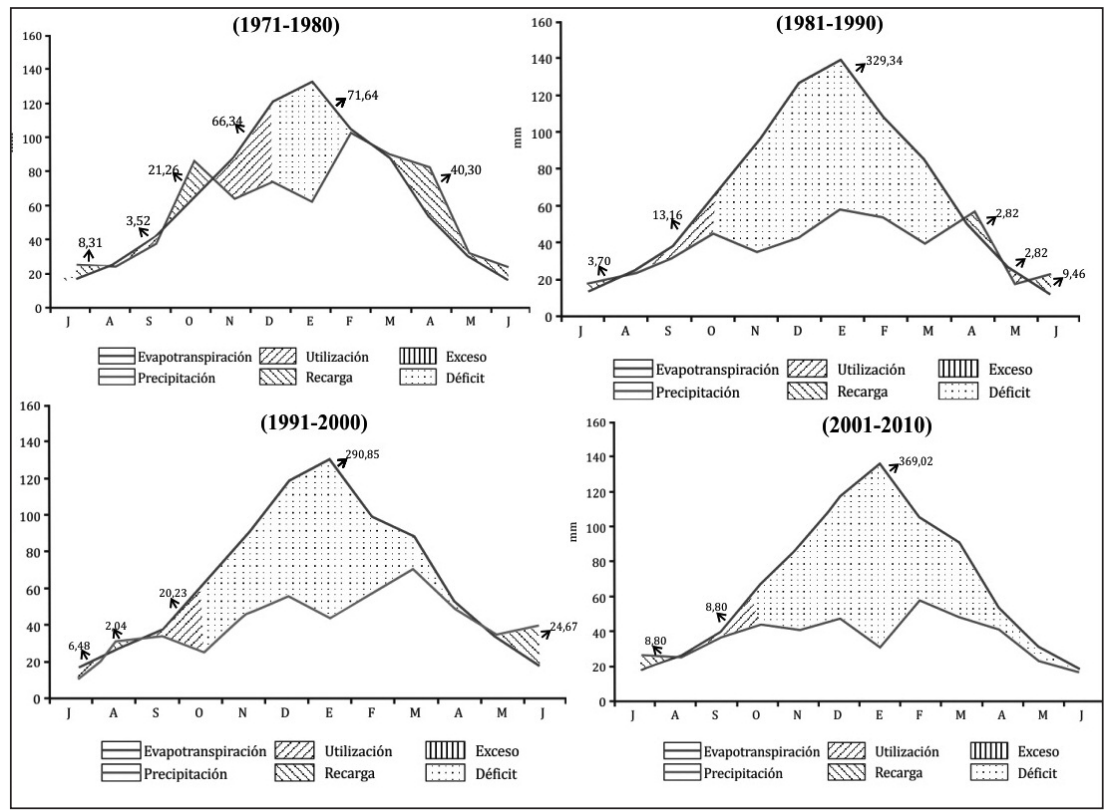

Fuente: elaborado por Julia Gabella, 2014.

Estudios Geográficos, Vol. LXXVII, 281, pp. 491-519, julio-diciembre 2016

ISSN: 0014-1496, eISSN: 1988-8546, doi: 10.3989/estgeogr.201616 
La ciudad de Viedma presenta un comportamiento similar que la de Ascasubi, por lo general con un mes menos de déficit, pero con un milimetraje de déficit mayor (Ascasubi: $264 \mathrm{~mm}$ y Viedma: $390 \mathrm{~mm}$ ). El déficit de agua se inicia también en el mes de octubre y se prolonga hasta abril. La recarga del suelo se concentra en los meses de invierno (mayo-julio, con un milimetraje promedio de 23,15 mm) y la utilización se produce de agosto a octubre (figura 7).

En la localidad de Viedma se observó a lo largo de los años, un comportamiento más regular que en la localidad de Ascasubi. Hacia el sur, más alejado de la zona de transición, el comportamiento de las precipitaciones suele ser más estable sin demasiadas variaciones. Esto se observa en el monto anual de precipitaciones reflejado también en las figuras de los balances.

\section{FIGURA 7}

BALANCES HÍDRICOS DE VIEDMA (1971-2010)

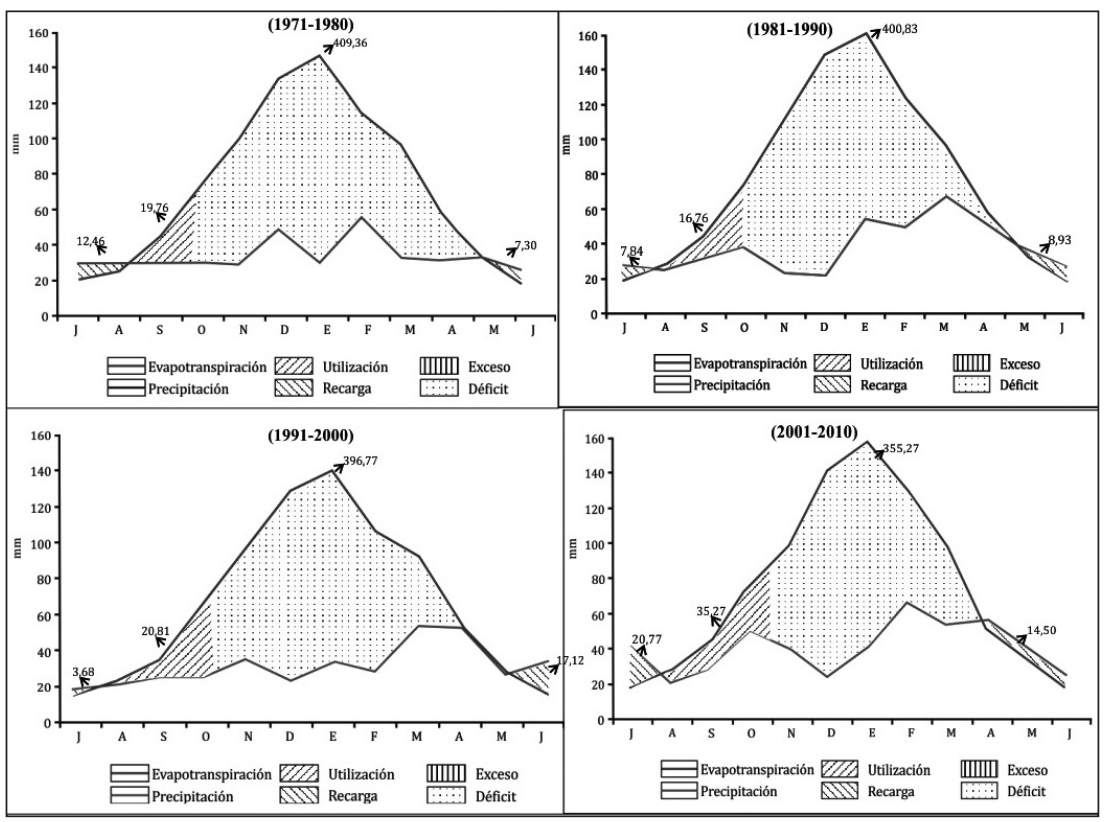

Fuente: elaborado por Julia Gabella, 2014.

La clasificación climática en función del índice hídrico demuestra que Hilario Ascasubi presentó una sola década en la cual los valores quedaron incluidos dentro del tipo de clima Subhúmedo Seco $(\mathrm{Cl})$, asociado a precipita- 
ciones anuales registradas para ese período, superiores a la media histórica de $712 \mathrm{~mm}$. El resto de los años analizados y en ambas localidades, los valores correspondieron al clima Semiárido (D). La misma, si bien engloba a ambas localidades, presenta ciertas diferenciaciones que se evidencian en la disparidad de los índices. Se observan valores menores a lo largo de las décadas e inferiores para la localidad de Viedma comparada con la de Ascasubi, lo que acentúa los rasgos significativos de aridez hacia el sur del área de estudio (tabla 2).

\section{TABLA 2}

CLASIFICACIÓN CLIMÁTICA EN FUNCIÓN DEL ÍNDICE HÍDRICO PARA LAS LOCALIDADES DE HILARIO ASCASUBI Y VIEDMA (1971-2010)

\begin{tabular}{llcl}
\hline Estación analizada & Décadas & Índice Hídrico & \multicolumn{1}{c}{ Clasificación } \\
\hline Hilario Ascasubi & $1971-1980$ & $-5,48$ & C1 (Subhúmedo seco) \\
\hline & $1981-1990$ & $-24,4$ & D (Semiárido) \\
\hline $1991-2000$ & $-21,96$ & D (Semiárido) \\
\hline Viedma & $-27,53$ & D (Semiárido) \\
\hline & $1971-1980$ & $-31,84$ & D (Semiárido) \\
\hline & $1981-1990$ & $-30,80$ & D (Semiárido) \\
\hline $1991-2000$ & $-30,95$ & D (Semiárido) \\
\hline
\end{tabular}

Fuente: elaborado por Julia Gabella, 2014.

La alternancia de ciclos húmedos y secos: cálculo y análisis del Índice de Precipitación Estandarizado (IPE)

De la observación de los datos obtenidos del IPE se distinguieron períodos bien definidos de valores negativos (que indican fases secas) y positivos (que indican fases húmedas) (figura 8). Del total de datos analizados los valores representaron un promedio en general de años normales $(-0,49$ a 0,49$)$ equivalente al 60\% del total de los 40 años. Los eventos considerados de moderados a severos en cuanto a excesos de precipitación representan el 21\% del total de años, mientras que las sequías moderadas a severas participan con un porcen- 
taje mayor (31\%) y una frecuencia de ocurrencia que se repite a lo largo de la serie en intervalos de 10 años.

Los extremos en el área asociados a valores por debajo de - 2 y mayor a 2 representan para ambos casos entre el 6 y $7 \%$ del total de años. La diferencia se observa que mientras las sequías extremas se registraron a principios de la serie $(1942,1950,1962,1971)$, los excesos o picos aislados de humedad extrema solo lo representan los años de las dos últimas décadas analizadas (1997, 1998, 2001 y 2004). Esto podría relacionarse con el aumento de las precipitaciones durante las últimas décadas, con valores por encima de la media histórica de la estación considerada $(404 \mathrm{~mm})$ y que se refleja en la línea de tendencia positiva (figura 8).

El análisis del IPE demuestra la alternancia y variación de las precipitaciones del área, con tendencias negativas frecuentes en la ocurrencia pero cortas en el tiempo, mientras que los excesos se asocian a periodos menos frecuentes pero más extensos en cuanto la cantidad de años registrados.

FIGURA 8

ÍNDICE DE PRECIPITACIÓN ESTANDARIZADO PARA STROEDER (1940-2010)

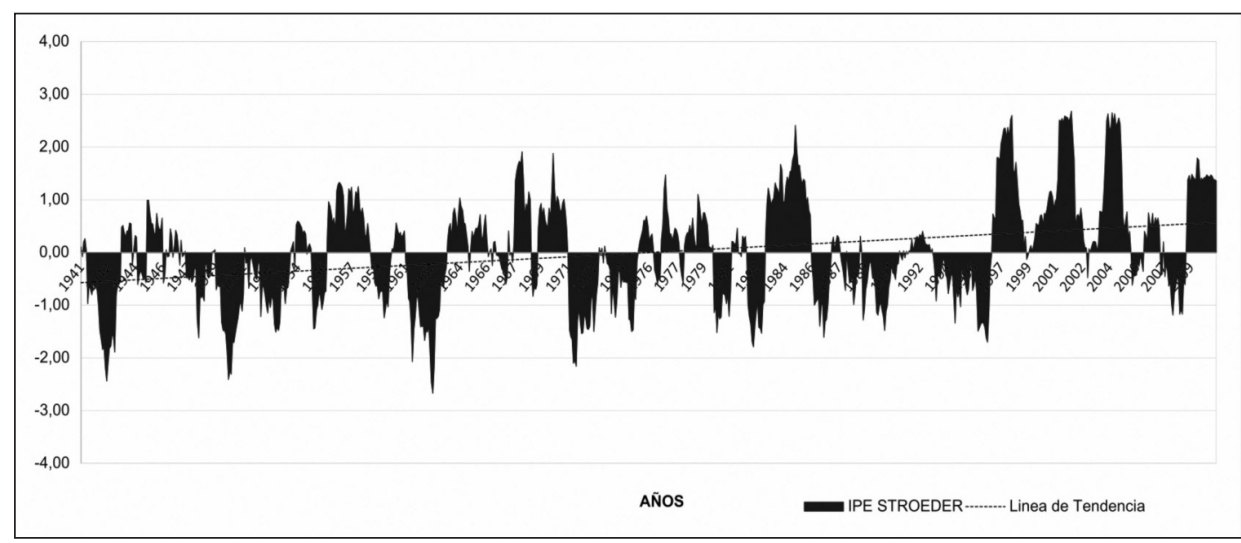

Fuente: elaborado por Julia Gabella, 2014.

La vinculación entre el modelo de gestión territorial y la degradación ambiental en el área

Las interacciones dinámicas que se producen entre los recursos disponibles, la sociedad que los explota y la tecnología que se utiliza para su explota- 
ción establecen, en cada momento histórico, un modelo de utilización del espacio rural. Esta utilización es el reflejo de las lógicas y racionalidades de cada tiempo y espacio en particular e influye en la calidad de vida de la población y las formas de modificación del medio ambiente (Navarrete et al., 2005).

Las escasas precipitaciones, fuerte vientos, suelos poco fértiles y un tapiz vegetal tupido y xerófilo, en definitiva, condiciones climáticas de aridez y semi-aridez, limitaron la evolución y el desarrollo de este espacio rural. Los acontecimientos histórico-climáticos y socioeconómicos influyeron y condicionaron las dinámicas territoriales del área, generando procesos conducentes a la degradación ambiental.

El aumento significativo de las precipitaciones en el período 1970-2000: la expansión de la frontera agrícola

A partir de la década del setenta comenzó a profundizarse un período más húmedo que abarcaría a la región semiárida bonaerense (Gabella y Del Pozo, 2009). La variación en el régimen de lluvias determinó la expansión gradual de la frontera agropecuaria y este avance se intensificó durante las siguientes décadas (Viglizzo et al., 2006; 2008).

Navarrete et al. (2005) afirman que la extrapolación del modelo productivo de la pampa a regiones extra-pampeanas ha presentado características evidentes de insostenibilidad ambiental, socio-cultural y productiva. Este proceso denominado «agriculturización» se definió como «el uso creciente y continuo de las tierras para cultivos agrícolas en lugar de los usos ganaderos o mixtos [...] y se asocia también a cambios tecnológicos, intensificación ganadera, expansión de la frontera agropecuaria hacia regiones extra-pampeanas y la tendencia de la agricultura hacia el desarrollo de producciones orientadas al monocultivo» (Navarrete et al., 2005: 7).

En cuanto a la variabilidad de la precipitación en el territorio argentino Hoffmann et al. (1987) demostraron el corrimiento de las isohietas hacia el oeste en aproximadamente $200 \mathrm{~km}$ durante el siglo pasado y Viglizzo (1997) correlacionan las curvas de precipitaciones y curvas de producción demostrando la coincidencia entre la agriculturización y el aumento de lluvias. Ambas curvas varían de forma relacionada, lo que indica que la agricultura se desplazó en los últimos años siguiendo la distribución de las precipitaciones. El avance de la frontera agrícola en el partido de Patagones aceleró el desmonte de grandes extensiones de «monte», término con el que se define generalmente a la vegetación nativa del área. 
Durante las décadas de los años setenta a los noventa, alcanzada la mecanización en casi la mayoría de los productores de la zona, las explotaciones modificaron paulatinamente sus estructuras productivas. La continuidad de años más húmedos favoreció, junto a políticas económicas imperantes, a los cambios en el uso del suelo. Se abandonó la diversificación productiva, que caracterizaba a la estrategia dominante de la mayoría de los productores del área, disminuyó la superficie ganadera y creció la ocupada con cereales. Ello implicó una disminución de las rotaciones agrícolas-ganaderas con el consecuente deterioro de los suelos.

Eventos climáticos extremos: las grandes sequías

En las regiones áridas y semiáridas, a diferencia de las regiones húmedas, se observa una gran variabilidad en la ocurrencia y montos de las precipitaciones. La ausencia total o parcial de las mismas durante períodos prolongados conduce a la ocurrencia de sequías que impactan negativamente en aquellas áreas dedicadas a las actividades de producción primaria (Gabella et al., 2010). La sequía es un fenómeno natural que es entendido como una condición de clima anormalmente seco y su importancia radica en el efecto que ocasiona sobre la economía de una región, principalmente en áreas con predominio de actividades agrícolas y ganaderas (Ferrelli et al., 2012).

El área de estudio presenta una alternancia de eventos asociados a déficit y excesos de precipitación y los extremos están relacionados mayormente a eventos de sequías, tornándose de severas a extremas. Las mismas han ocasionado pérdidas irreparables en las economías de los pequeños y medianos productores, mientras que la ocurrencia de precipitaciones normales y a veces más húmedas que las habituales trajeron aparejadas buenas cosechas y mayores posibilidades de modernización y utilización de tecnología.

El partido de Patagones es un espacio frágil, de transición climática, por lo que exhibe una mayor susceptibilidad a los problemas erosivos. Si bien presenta precipitaciones medias anuales de $407 \mathrm{~mm}$ estas varían año a año. Según Ferrelli et al. (2012) el análisis del método de quintiles para la determinación de años secos, húmedos y normales, caracterizó a los años 2005, 2007, 2008 y 2009 como «muy secos». La distribución espacial de las precipitaciones fue similar en toda la región registrándose los menores valores para el período 2008-2009 (inferiores a $300 \mathrm{~mm} / \mathrm{año}$ ) (Del Barrio et al., 2013; Ferrelli et al., 2012) (tabla 3). Esos años de sequías desencadenaron una crisis que en el año 2009 produjo graves impactos, como pérdidas en las cosechas, disminución del número de cabezas de ganado vacuno y erosión eólica del suelo (Ferrelli et al., 2012). 
TABLA 3

PRECIPITACIÓN MEDIA ANUAL DEL PARTIDO DE PATAGONES (2005-2009)

\begin{tabular}{cc}
\hline Año & Precipitación Media Anual (mm) \\
\hline 2005 & 289,5 \\
\hline 2006 & 440,6 \\
\hline 2007 & 300,6 \\
\hline 2008 & 217,6 \\
\hline 2009 & 215,4 \\
\hline
\end{tabular}

Fuente: elaborado por Julia Gabella, 2014 sobre la base de registros pluviométricos obtenidos del Ministerio de Asuntos Agrarios para las localidades de Cardenal Cagliero, Carmen de Patagones, José B. Casás, Stroeder y Villalonga.

La continuidad de años de extrema y extendida sequedad agotaron las reservas de humedad en los campos. Los suelos desmontados perdieron la capacidad de absorber humedad y desapareció el pastizal natural. La erosión y el aporte del material en suspensión también afectaron a aquellas áreas no desmontadas debido a que la voladura de suelos, nubes de tierra y tormentas de arena y viento eran frecuentes y dificultaban la visibilidad y transitabilidad de la zona.

Es importante destacar que si bien el área había tenido reiterados ciclos de precipitaciones inferiores a la media, con años de sequías intensas, no se había registrado hasta ese momento, una crisis de tal magnitud. Esto fue el resultado de años consecutivos de desmontes y prácticas agropecuarias poco sustentables con el medio natural. El análisis del IPE realizado demostró que para el periodo 1940-2010 los valores más extremos asociados a sequías no coincidieron con los últimos años. Durante los años 2005-2009 se manifestaron valores negativos pero en ningún caso los mismos alcanzaron la categoría de sequías severas o extremas como las registradas en décadas anteriores (1942, 1950, 1962, 1971) (figura 9). 
FIGURA 9

EVENTOS DE SEQUÍAS EXTREMAS EN EL PARTIDO DE PATAGONES (1940-2010)

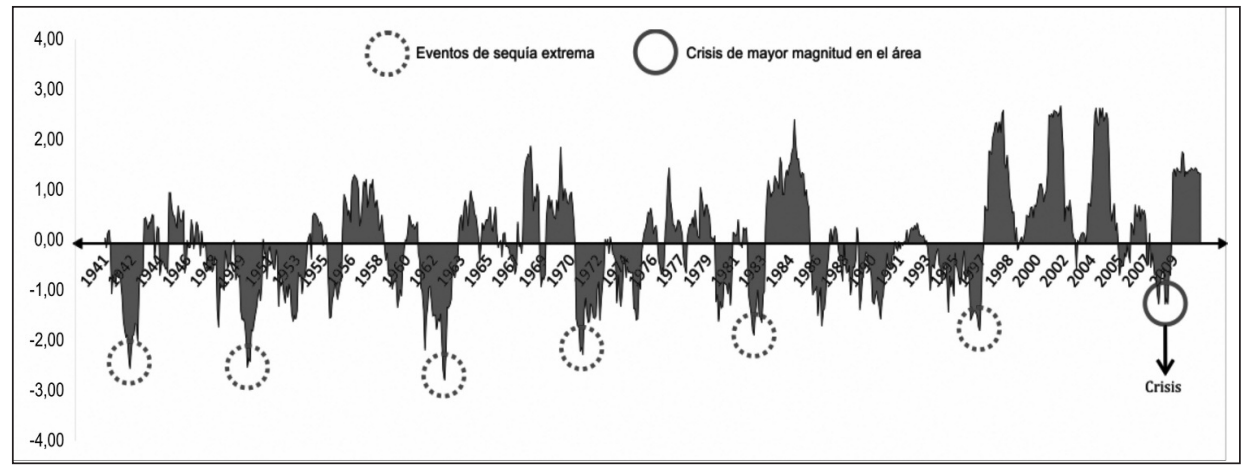

Fuente: elaborado por Julia Gabella, 2014.

La degradación ambiental en el área

En la ocupación de este espacio rural existió una desconexión permanente entre el binomio condiciones climáticas-medio natural y los sistemas de producción-explotación. La falta de adaptación a las características imprevisibles del clima generó graves consecuencias socioeconómicas. La variabilidad en las precipitaciones sumado al desconocimiento de los productores y manejos productivos poco sustentables fueron factores que se repitieron históricamente, potenciando y acrecentando los problemas en la región. Hoy en día, a pesar de las nuevas tecnologías y la mejora en la genética de las semillas implementadas, el pequeño y mediano productor sigue enfrentándose a la misma situación de vulnerabilidad ante los eventos climáticos ya que persiste una lógica de producción no compatible con el medio natural.

La dinámica productiva del territorio en la actualidad se basa en actividades agrícolas y ganaderas existiendo una gran diferencia entre el este y el oeste del partido. El meridiano $63^{\circ}$ divide, al igual que la Ruta Nacional $N^{\circ} 3$, al partido en dos. Hacia el este, los suelos con mayor influencia marítima suelen ser los más aptos para la agricultura. Hacia el oeste, adentrándose hacia el interior del continente, se hacen presentes rasgos de mayor aridez, que se manifiestan en las características de los suelos y la vegetación, constituyéndose en espacios menos aptos para la agricultura. Se identifican así, zonas con características bien diferenciadas en cuanto a la distribución y usos del suelo en el partido. 
La zona norte aledaña al río Colorado, corresponde al área de riego, dedicada a la producción hortícola-ganadera es el área más dinámica del partido. En la zona de secano se diferencia hacia el oeste, el área de monte nativo dedicada mayoritariamente a la ganadería extensiva de recría y ciclo completo. Aquí las superficies de explotación son mayores a las 2.000 ha y hacia el este existe un área de aproximadamente 510.000 ha desmontada y orientada básicamente a la agricultura triguera. En este sector y en cercanías de los poblados se visualizan superficies de explotación más pequeñas (menores a las 1.000 ha) dedicadas a la actividad agrícola o agrícola-ganadera.

\section{FIGURA 10}

\section{ZONIFICACIÓN APROXIMADA DE LAS PRINCIPALES ÁREAS PRODUCTIVAS DEL PARTIDO DE PATAGONES}

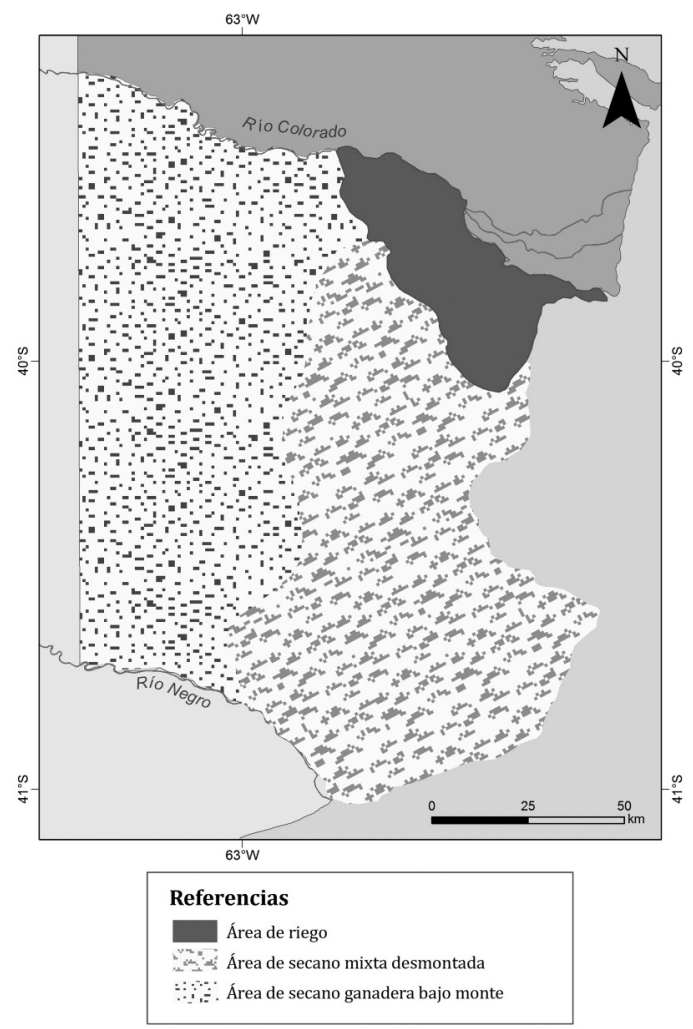

Fuente: elaborado por Julia Gabella 2014 sobre la base de Iurman, 2009.

Estudios Geográficos, Vol. LXXVII, 281, pp. 491-519, julio-diciembre 2016

ISSN: 0014-1496, eISSN: 1988-8546, doi: 10.3989/estgeogr.201616 
El resto de la superficie lo ocupa la franja costera atlántica (Zingoni y Bustos, 2007). La figura 10 representa la localización relativa de las principales áreas productivas del partido, según datos relevados y obtenidos en el Laboratorio de Teledetección y SIG de la Estación Experimental Agropecuaria Hilario Ascasubi (INTA).

La estructura y dinámica productiva del sector primario la constituyen la actividad agrícola junto con la ganadería y representan la base de sustentación de la economía del partido. En el área de secano, espacio geográfico central de este estudio, la diversificación productiva es escasa. El principal cultivo de cosecha es el trigo representando el $90 \%$ de los cereales cosechados, con una producción aproximada de 120.000 a 140.000 t/ha de cereal y en segundo lugar la avena y el centeno, estos últimos utilizados para la realización de verdeos. Según Iurman (2009) en el área desmontada, la ganadería juega un papel secundario donde se realiza cría, recría y engorde. La actividad ganadera se constituye principalmente por ganado bovino y ovino y se desarrolla sobre los verdeos, las pasturas y los pastizales naturales. En los últimos años ha surgido una recuperación de la producción ovina y un incipiente crecimiento de los cultivos de olivo, producción porcina y aromática.

Desde los inicios de la actividad agropecuaria en la región y tras el auge del modelo agroexportador, las modificaciones registradas en el uso del suelo han afectado al medio ambiente. El equilibrio natural se fue alterando como resultado de las orientaciones productivas que se sucedieron en el tiempo. La explotación de especies arbóreas nativas en el área de estudio fue intensa. Algunos sectores fueron altamente modificados y gran parte del bioma fue alterado por la excesiva caza de su fauna y el destructivo sobrepastoreo del ganado ovino y bovino (Bruniard, 2004; De Lucca, 2011).

El avance de la frontera agrícola sobre el monte nativo ha sido evidente. Las tierras agrícolas de secano representaban en el año 1975 el 25,7\% del total de la superficie del partido. En 2009 este porcentaje se incrementó hacia un 49,1\%. Pezzola et al. (2009) afirman en sus estudios que en el año 2009 la vegetación nativa había sido reducida a un $30 \%$ de la superficie total del partido y para el 2011 este porcentaje se redujo a un 20\%, con la deforestación de 153.263 ha más en tan sólo dos años (tabla 4).

La pérdida de la vegetación nativa genera a su vez pérdida de biodiversidad. El monte es el hábitat de una gran variedad de flora y fauna silvestre y su destrucción implica el riesgo de extinción de numerosas especies y provoca desequilibrios ecológicos en el ecosistema (Villagra et al., 2004). La vegetación natural desempeña un papel fundamental en la lucha contra la degrada- 
ción del suelo y la vegetación perenne garantiza una protección eficaz y duradera del mismo. La deforestación incrementa la vulnerabilidad de las tierras hacia la desertificación (Salluso, 2008).

TABLA 4

EVOLUCIÓN DEL DESMONTE EN EL PARTIDO DE PATAGONES EN HECTÁREAS Y PORCENTAJE DE MONTE EN SUPERFICIE TOTAL DEL PARTIDO (1975-2011)

\begin{tabular}{ccc}
\hline Año & Superficie de Monte en ha & \% de Monte en superficie \\
\hline 1975 & 911.171 & 65 \\
\hline 1987 & 682.367 & 49 \\
\hline 1999 & 554.138 & 40 \\
\hline 2002 & 524.629 & 37 \\
\hline 2005 & 437.134 & 31 \\
\hline 2009 & 432.280 & 20 \\
\hline 2011 & 279.017 & 20 \\
\hline
\end{tabular}

Fuente: elaborado por Julia Gabella, 2014. Modificado de Pezzola et al., 2004.

El INTA elaboró un informe donde evaluó los suelos erosionados del partido para el año 2009. Se clasificó en tres grados de severidad de erosión y se determinó la superficie para cada uno de ellos. Los resultados evidenciaron que de las 683,46 ha de superficie bajo un uso mixto agrícola-ganadero, los suelos erosionados representaron 393.511 ha. Esto equivale aproximadamente al 60\% del total de la superficie destinada a la producción de secano en el partido. Las superficies erosionadas bajo las categorías consideradas de moderado a grave y de grave a severo cubrían para ese año el 50\% del área con 346.174 ha.

En coincidencia con los estudios de Ferrelli et al. (2012) el conjunto de factores antrópicos como la expansión de la frontera agropecuaria y el uso irracional del suelo; la deforestación y sustitución del ecosistema nativo, su- 
mado a la existencia de un fenómeno natural como las sequías, generaron la disminución de la biodiversidad natural y la degradación de los suelos, factores que favorecieron los procesos de desertificación.

En los últimos años se observó un significativo aumento de la migración desde las zonas rurales hacia las ciudades cabeceras. El abandono de la tierra se tradujo en la pérdida de la actividad económica en aquellas familias que no lograron reinsertarse adecuadamente al sistema productivo, generando a su vez pérdidas de oportunidades, desarraigo y dependencia de las medidas paliativas ofrecidas por el estado. Quienes emigraron constituyeron la población económicamente activa dejando atrás una población altamente dependiente de las transferencias familiares o del estado (OPDS, 2012).

En el partido se produjo una sensible reducción en el número de las explotaciones agropecuarias. Entre los censos agropecuarios de 1988 y $2002^{4}$ la disminución en el número de Explotaciones Agropecuarias (EAPs) fue significativa, alcanzando un 13,8\% lo que representó 148 explotaciones menos en el partido. Esta reducción fue producto del mencionado círculo vicioso de degradación y descapitalización que llevó al abandono y al éxodo rural. Estos procesos generaron un descenso de la población, que trajo como consecuencia características espaciales que se expresaron en la pérdida de servicios y equipamiento, el desaprovechamiento y envejecimiento de la capacidad productiva instalada y fueron provocando, poco a poco, la fragmentación del espacio rural (Gabella y Álamo, 2013).

\section{CONCLUSIONES}

La variabilidad climática del área manifestada en la alternancia de períodos húmedos y secos condicionó en determinados momentos la evolución y el desarrollo del partido, modificando las estructuras agrarias, los sistemas productivos y las formas de gestión agropecuaria. Las áreas rurales pertenecientes al partido de Patagones se vieron influenciadas al igual que otras áreas de la diagonal árida templada argentina por diferentes modelos de desarrollo que a través de sus tendencias políticas, económicas, tecnológicas y culturales lograron condicionar, influenciar y determinar en algunos casos, la dinámica y evolución de las áreas rurales.

${ }^{4}$ En la actualidad se sigue utilizando el Censo Nacional Agropecuario realizado en el año 2002, porque el del 2008 en cuanto al relevamiento de la información, no fue abarcativo de la zona, por lo tanto no se considera una fuente de información confiable. Esto evidencia la desactualización de los datos con los que se cuenta para realizar estudios o idear políticas. 
La ecuación de la degradación ambiental en el partido de Patagones es compleja, variable y dinámica e involucra tres aspectos de una misma realidad: el natural, con la deforestación del monte nativo y alteraciones en las características físicas y químicas del suelo generando desertificación y pérdida de biodiversidad; el económico, con el endeudamiento de los productores rurales y la consecuente pobreza rural y; el aspecto socio-cultural, donde la degradación se asocia al abandono de tierras, éxodo rural y la pérdida de valores y tradiciones culturales.

\section{BiBLIOGRAFÍA}

Bohn, V., Piccolo, C. y Perillo, G. (2011): "Análisis de los periodos secos y húmedos en el sudoeste de la provincia de Buenos Aires (Argentina)", Revista de Climatología, 11, pp. 31-43.

Bruniard, E. (1982): "La diagonal árida: un límite climático real", Revista Geográfica, 95, pp. 5-20.

Bruniard, E. (1999): Los regímenes hídricos de las formaciones vegetales. Aportes para un modelo fitoclimático mundial, Corrientes, Editorial Universitaria de la Universidad Nacional del Nordeste, $382 \mathrm{pp}$.

Bruniard, E. (2004): Clima, paisaje y geografia, Corrientes, Editorial Universitaria, $103 \mathrm{pp}$.

Campo, A., Capelli, A. y Diez, P. (2004): El clima del Sudoeste Bonaerense, Bahía Blanca, EdiUns, 99 pp.

Campo, A., Ramos, M. y Zapperi, P. (2009): "Análisis de las variaciones anuales de precipitación en el Suroeste bonaerense, Argentina”, XII Encuentro de Geógrafos de América Latina, Montevideo, Ed. Universidad de la República, p. 12.

Capelli de Stefens, A., Ockier, C. y Petagna, A. (1979): "Determinación de estructuras atípicas en un área de transición”, Cuadernos Del Sur, 12, p. 30.

Capelli de Steffens, A. y Campo de Ferreras, A. (1994): "La transición climática en el sudoeste bonaerense", Sigeo, 5, p. 75.

Chiozza, E. y Figueira, R. (1981): "Atlas Físico de la República Argentina", en Atlas Total de la República Argentina, Buenos Aires, Centro Editor de América Latina, vol. 1, p. 192.

De Lucca, E. (2011): "Presencia del Puma (Puma Concolor) y su conflicto con el hombre en el partido de Patagones, Buenos Aires, Argentina", Notas Faunísticas, Segunda serie, 67, pp. 1-13.

Del Barrio, R., Martin, D. y Calvo, D. (2013): "Tendencia de las lluvias y las temperaturas en el noroeste patagónico: variabilidad o cambio climático", en Ambiente, sociedad y producción, Viedma, Universidad Nacional de Río Negro, p. 15.

Duval, V., Volonté, A., Ramos, M. y Campo, A. (2012): "Fluctuaciones de los meses 
con sequía en el suroeste bonaerense para el período 1981-2010", en IX Jornadas Nacionales de Geografía Física, Bahía Blanca, EdiUns, pp. 185-196.

Ferrelli, F., Bohn, V. Y. y Piccolo, M. C. (2012): "Variabilidad de la precipitación y ocurrencia de eventos secos en el sur de la provincia de Buenos Aires", en IX Jornadas Nacionales de Geografía Física, Bahía Blanca, EdiUns, pp. 15-28.

Gabella, J., Gil, V. y Del Pozo, O. (2009): "Historia Ambiental del área rural de Pelicurá, sobre la base de registros pluviométricos. Partido de Tornquist, provincia de Buenos Aires", Revista Universitaria de Geografía (RUG), 18, pp. 81-104.

Gabella J. y Álamo, M. (2013): "La incidencia de las políticas agropecuarias en el desarrollo rural del partido de Patagones en los últimos diez años (2003-2013)", Revista Interdisciplinaria de Estudios Sociales, 7, pp. 11-39.

Gabella, J., Zapperi, P. y Campo, A. (2010): "Distribución estacional de las precipitaciones en el Suroeste Bonaerense", en VII Jornadas Nacionales de Geografía Física de la República Argentina, Posadas, Ed. Universidad Nacional de Misiones, pp. 8794.

Gil, V., Zapperi, P. y Campo, A. (2008): "Análisis de las precipitaciones de otoño y primavera en el Suroeste bonaerense", en VII Jornadas de Geografía Física, San Salvador de Jujuy, Universidad Católica de Santiago del Estero, pp.1-12.

Glave, A. (2006): "Influencia climática en el sudoeste bonaerense y sudeste de La Pampa", ACAECER, 31/360, pp.18-23.

Hernández Sampieri, R. (2003): Metodología de la Investigación, Santiago de Chile, Ed. Mc Graw-Hill, 839 pp.

Hoffmann, J., Núñez, S. y Gómez, A. (1987): "Fluctuaciones de la precipitación en la Argentina en lo que va del siglo", en II Congreso Interamericano de Meteorología, Buenos Aires, Centro Argentinos de Meteorólogos, pp. 1-20.

Iurman, D. (2009): "Diagnóstico y evaluación económica de alternativas tecnológicas para productores agropecuarios familiares de la zona de secano del partido de $\mathrm{Pa}$ tagones", tesis de Magister economía agraria y administración rural, Bahía Blanca, Universidad Nacional del Sur, $195 \mathrm{pp}$.

Köppen, W. y Geiger, R. (1936): "Das geographische System der Klimate”, Handbuch der Klimatologie, 1, pp.1-44.

Madsen, L. y Adriansen, H. (2004): "Understanding the use of rural space: the need for multi- methods", Journal of Rural Studies, 20, pp. 485-497.

Mancini, M., Paez, M. y Prieto, A. (2004): "Mid-Holocene climatic variability reconstruction from pollen records $\left(32^{\circ}-52^{\circ} \mathrm{S}\right.$, Argentina)", Quaternary International, 132, pp. 47-59.

Mckee, T. (1993): "The relationship of drought frecuency and duration to time scales", en 8th. Conference on Applied Climatology, Anaheim, American Meteorological Society, pp. 179-184.

Navarrete, M., Gallopín, G., Blanco, M., Díaz-Zorita, M., Ferraro, D. et al. (2005): "Análisis sistémico de la agriculturización en la pampa húmeda argentina y sus consecuencias en regiones extra-pampeanas: sostenibilidad, brechas de conoci- 
miento e integración de políticas”, en División de Desarrollo Sostenible y Asentamientos Humanos. Serie: medio ambiente y desarrollo, Santiago de Chile, CEPAL, p. 118.

Organismo Provincial sobre el Desarrollo Sustentable (OPDS) (2012): "Proyecto Incremento de la Resiliencia Climática y Mejora de la Gestión Sustentable del Suelo en el Sudoeste de la Provincia de Buenos Aires. Argentina", en Secretaria de Ambiente y desarrollo sustentable de la nación, La Plata, OPDS, p. 48.

Papadakis, J. (1978): Mapa ecológico abreviado de la República Argentina, Buenos Aires, Ministerio de Agricultura y Ganadería, 79 pp.

Peña Zubiate C., Anderson D. y Demmi, M. (1998): Carta de suelos y vegetación de la provincia de San Luis, San Luis, INTA, $115 \mathrm{pp}$.

Petagna del Río, A. y Ferrera, I. (1998): "Régimen jurídico sobre la distribución de la tierra en el diseño del espacio rural. La problemática en el área de transición pradera-monte", La Pampa-Buenos Aires-Rio Negro, Revista Universitaria de Geografía, 7, pp. 11-27.

Pezzola, A., Agamennoni, R. y Winschel, C. (2009): "Estimación expeditiva de suelos erosionados del partido de Patagones. Provincia de Buenos Aires", INTA Hilario Ascasubi, 20, p. 7.

Pezzola, A., Winschel, C. y Sanchez, R. (2004): Estudio multitemporal de la degradación del monte nativo en el partido de Patagones, INTA Hilario Ascasubi, Buenos Aires, INTA, p. 11.

Piccolo, M., Capelli, A. y Campo, A. (2002): "La sequía de 1995 en el sur de la región pampeana argentina", en Desastres Naturales en América Latina, Buenos Aires, Fondo de Cultura Económica, pp. 189-206.

Salluso, M. (2008): Regulación Ambiental: Los Bosques Nativos. Una visión Económica, Buenos Aires, Universidad de Belgrano, 90 pp.

Sánchez, R., Pezzola, N. y Cepeda, J. (1998): Caracterización edafoclimática del área de influencia del INTA E.E.A. Ascasubi, Buenos Aires, INTA, 114 pp.

Secretaria de ambiente y desarrollo sustentable (2006): "Primer Inventario Nacional de Bosques Nativos. Segunda Etapa”, Buenos Aires, Dirección de Bosques, Coordinación Bosques Nativos, 77 pp.

Sili, M. (2000): Los Espacios de la Crisis Rural. Geografía de una Pampa Olvidada, Bahía Blanca, EdiUns, 195 pp.

Thornthwaite, C. W. y Mather, J. R. (1957): Instructions and tables for computer potential evapotranspiration and the water balance, USA, CW Thornthwaite Associates, $60 \mathrm{pp}$.

Verbist, K., Santibañez, F. y Soto, G. (2010): “Atlas de Zonas Áridas de América Latina y el Caribe”, Programa Hidrológico Internacional (PHI), 25, Uruguay, UNESCO, p. 48.

Viglizzo, E. (1997): "Climate and land use change in field-crop ecosystems of Argentina”, Agriculture, Ecosystems \& Environment, 66, pp. 61-70.

Viglizzo, E., Frank, F., Bernardos, J., Buschiazzo, D. y Cabo, S. (2006): “A rapid 
method for assessing the environmental performance of commercial farms in the Pampas of Argentina", Environmental Monitoring and Assessment, 117, pp.109-134. Viglizzo, F., Jobbagy, E., Carreño, L., Frank, F. y Aragón, R. (2008): "The dynamics of cultivation and floods in arable lands of Central Argentina", Hydrology and Earth System Sciences Discussions, 5, pp. 2.319-2.345.

Villagra, P., Cony, M., Mantován, N., Rossi, B., Gonzáles Loyarte, M. y Villalba, R. (2004): "Ecología y Manejo de los algarrobales de la Provincia Fitogeográfica del Monte", en Ecología y Manejo de Bosques Nativos de Argentina, La Plata, Editorial Universidad Nacional de La Plata, 32 pp.

Zingoni, J. y Bustos Cara, R. (2007): Plan Estratégico Participativo de Desarrollo Turístico Sustentable del Partido de Patagones, Buenos Aires, Secretaría de Turismo de la Nación, 458 pp.

Fecha de recepción: 5 de diciembre de 2014.

Fecha de aceptación: 9 de septiembre de 2015. 